\title{
APPLICABILITY OF BACTERIAL ENDOTOXIN TEST (BET) FOR SOME RADIOPHARMACEUTICAL STERILE KITS BY THE USE OF TACHYPLEUS AMEBOCYTE LYSATE (TAL)
}

\author{
Amal Rezka Putra ${ }^{1 *}$, Enny Lestari ${ }^{1}$, Dede Kurniasih ${ }^{1}$, Karyadi Karyadi ${ }^{1}$, Endang \\ Sarmini $^{1}$ and Arni Aries ${ }^{1}$
}

\author{
${ }^{1}$ Center for Radioisotope and Radiopharmaceutical Technology, National Nuclear Energy \\ Agency, Puspiptek Area, Tangerang Selatan, Banten, 15314, Indonesia.
}

Received January 15, 2019; Accepted May 26, 2019

\begin{abstract}
The application of bacterial endotoxin test (BET) using TAL reagent on radiopharmaceutical kits is very important to conduct. The radiopharmaceutical kits that will be tested are macro aggregated albumin (MAA), tetrofosmin and ethambutol kits. Endotoxin testing stage was TAL $0.25 \mathrm{EU} / \mathrm{mL}$ verification test, inhibition/enhancement test, and endotoxin test for sample. Pyrogen testing using rabbits was also performed as a comparison test. The results of the TAL reagent verification test were all samples showed values corresponding to the standards of $2 \lambda=(+), 1 \lambda=(+), 1 / 2 \lambda=(-), 1 / 4 \lambda=(-)$, and negative water control $($ NWC $)=(-)$. Furthermore, inhibition/enhancement tests for MAA, tetrofosmin, and ethambutol products show non-inhibiting or gel-inducing results, which are in accordance with acceptability standards, so that the samples can be tested using TAL reagents. The $\mathrm{pH}$ measurement results in each sample were MAA of 6.0, tetrofosmin of 7.0, and ethambutol of 8.0. The results of MAA, tetrofosmin, and ethambutol product testing were a sample $=(-)$, positive product control $(\mathrm{PPC})=(+)$, positive water control $(\mathrm{PWC})=(+)$, and NWC $=(-)$. In addition, the results of pyrogen testing also showed negative for MAA, tetrofosmin, and ethambutol.
\end{abstract}

Keywords: Bacterial endotoxin test (BET); Radiopharmaceutical kit; Tachypleus amoebocyte lysate (TAL)

\section{INTRODUCTION}

The radiopharmaceutical is a pharmaceutical preparation labeled with radionuclide so that its energy can be used as a diagnosis or therapy in the field of nuclear medicine (Scott and Kilbourn, 2015; Knapp and Dash, 2016). Radiopharmaceutical preparations are generally injected intravenously (Salmanoglu, Kim and Thakur, 2018). Therefore, the classification of the radiopharmaceutical preparation must meet the criteria of a sterile pharmaceutical preparation. One of the requirements of sterile preparations is pyrogen-free or endotoxin-free (Zandieh et al., 2018). Pyrogen is a substance that can cause fever, and generally in pharmaceutical products it comes from gram-negative bacteria (Lopes et al., 2015; Silva et al., 2016) while endotoxin is a complex compound consisting of pyrogenic lipopolysaccharides (Zandieh et al., 2018).

The pyrogen-free test was initially conducted using rabbits. However, since it is known that endotoxins are able to agglomerate limulus blood cells, then in the development to detect endotoxins an alternative pyrogen test was found which is a bacterial endotoxin test using limulus

*Corresponding author: Amal Rezka Putra

Email: amalrezka@batan.go.id 
amoebocyte lysate (LAL) (Miao et al., 2013). The bacterial endotoxin test was first performed by Frederik B. Bang with the freezing method of LAL cells that are sensitive to endotoxins (Bang, 1971). The application of endotoxin test in various sterile preparations has been done routinely for several decades in a number of countries. In the 1980s the United States approved the endotoxin test as a substitute of pyrogen testing for end-products of parenteral drugs and this change subsequently was followed by other countries (Ochiai et al., 2010).

Many new methods have emerged to replace the role of animal experiments in routine quality control tests such as pyrogenic test transfers to endotoxin test using the monocyte activation test (MAT) (Silva et al., 2016). The need for LAL reagents is very high so that another source of lysate has been required. Therefore, the presence of a very large tachypleus amoebocyte lysate (TAL) horseshoe lysate in Southeast Asia may be an alternative source of lysate for bacterial endotoxin testing (John et al., 2012; Li, Hitchins and Wickramasekara, 2016).

Several radiopharmaceutical kits have been developed in Indonesia, for example, the macro aggregated albumin (MAA) kit used for the diagnosis of pulmonary perfusion (Lestari, 2017), tetrofosmin kit for cardiac diagnosis (Widyastuti, Lestari and Sangaji, 2017) and the ethambutol kit used for the diagnosis of mycobacterium tuberculosis (MBT) in the body (Juwita, 2009). The radiopharmaceutical kits have undergone strict quality control, but the pyrogen test still uses rabbits that require animal maintenance and care which can pose some difficulties, since the sensitivity of the test results is affected by the environment, and the observation time is also so long that the test becomes ineffective. A study of bacterial endotoxin test for 18F-Fludeoxyglucose (FDG) was conducted by Sharma, et al. (2011). Therefore, endotoxin tests are routinely performed using TAL for radiopharmaceutical products which are more effective in test time and not influenced by external factors of rabbit test animals. The object of this research was to apply bacterial endotoxin test (BET) using TAL reagent with a sensitivity of 0.25 $\mathrm{EU} / \mathrm{mL}$ on radiopharmaceutical kit preparation such as MAA, tetrofosmin, and ethambutol.

\section{METHODS}

\section{Equipment}

Equipment used in this research included syringe $1 \mathrm{~mL}$ (BD), micropipette and tips (Eppendorf), digital tele thermometer model 461 (Electronics India), stopwatch, vial, thermo mixer comfort as an incubator (Eppendorf), analog vortex mixer (VWR International)

\section{Materials}

Materials used in this research were local rabbit (Oryctolagus cuniculus) identified as the white New Zealand rabbit, which weighs about $2.5-3.5 \mathrm{~kg}$, and initial body temperature of $37.0-39.8^{\circ} \mathrm{C}$, a set of endotoxin detection kits, gel-clots: Tachypleus amoebocyte lysate (TAL), control standard endotoxin (CSE), sterile water free pyrogenic (BET water) (Zhanjiang Bokang Marine Biological Co., Ltd., China), MAA, tetrofosmin, and ethambutol sample kits are manufactured by the Center for Radioisotope and Radiopharmaceutical Technology (PTRR)National Nuclear Energy Agency (BATAN).

\section{Bacterial Endotoxin Test by using TAL TAL verification test}

Control standard endotoxin (CSE) dilution was done from preparations of 10 EU/mL. CSE was resuspended using $1 \mathrm{~mL}$ BET water, then the suspension was homogenized for 15 minutes. The CSE suspension was then diluted into a standard solution used for the confirmation test. Standard solutions were diluted to concentrations $1 \mathrm{EU} / \mathrm{mL}(4 \lambda), 0.5 \mathrm{EU} / \mathrm{mL}$

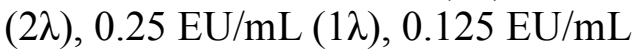


$(1 / 2 \lambda)$, and $0.0625 \mathrm{EU} / \mathrm{mL}(1 / 4 \lambda)$. Then each concentration and negative water control (BET water) was inserted into the TAL reagent. Then it was incubated at $37 \pm$ $1^{\circ} \mathrm{C}$ for $60 \pm 2$ minutes without vibration. The samples were tested positive for endotoxin (>0.25 EU/mL) when the gel was formed and negative endotoxin $(<0.25$ $\mathrm{EU} / \mathrm{mL}$ ) were not formed after the tube was reversed 180 degrees slowly (USP $35-\mathrm{NF}$ 30 online version, 2012). The dilution scheme for BET verification test is shown in Figure 1.

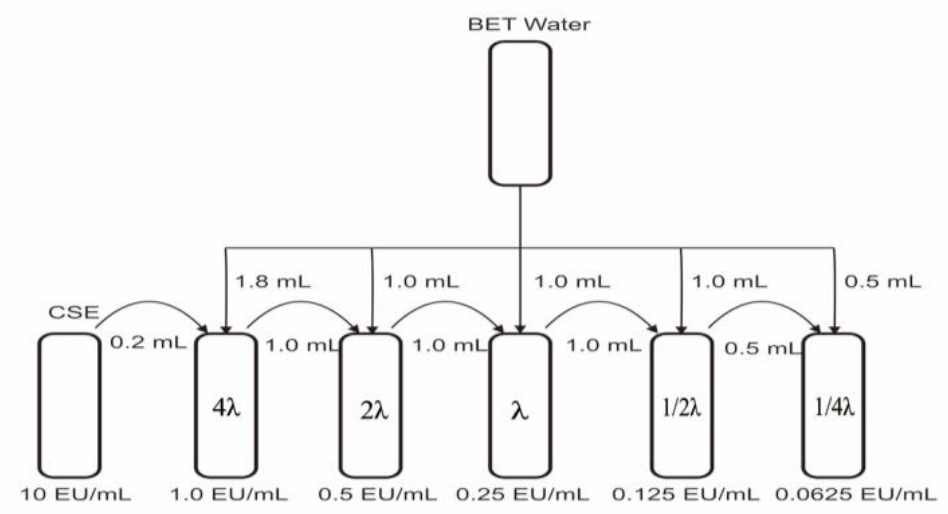

Figure 1. Bacteria endotoxin concentration for the verification test

Test Inhibition / enhancement.

The sample was first tested whether the substance inhibits or induces gel formation in TAL. Each solution contained the composition according to the Table I. Then the sample solutions $\mathrm{A}, \mathrm{B}, \mathrm{C}$, and $\mathrm{D}$ were incubated at $37 \pm 1{ }^{\circ} \mathrm{C}$ for $60 \pm 2$ minutes without vibration. The samples were tested positive when the gel was formed and negative samples were not formed after the tube was reversed 180 degrees slowly (USP 35-NF 30 online version, 2012). Where, solution $\mathrm{A}$ is a sample solution of the preparation under test that is free of detectable endotoxins, solution $\mathrm{B}$ is test for interference, solution $\mathrm{C}$ is control for labeled TAL reagent sensitivity, and solution $\mathrm{D}$ is negative control of BET water.

Table I. Preparation of solution for the Inhibition / Enhancement test for gel clot technique

\begin{tabular}{lllcc}
\hline Solution & \multicolumn{1}{c}{$\begin{array}{c}\text { Endotoxin } \\
\text { concentration }\end{array}$} & $\begin{array}{c}\text { Solution to which } \\
\text { endotoxin is added }\end{array}$ & $\begin{array}{c}\text { Initial endotoxin } \\
\text { concentration }\end{array}$ & $\begin{array}{c}\text { Number of } \\
\text { replicates }\end{array}$ \\
\hline A & None & $0.2 \mathrm{~mL} \mathrm{Sample} \mathrm{solution}$ & - & 4 \\
\hline B1 & $0.1 \mathrm{~mL} 2 \lambda$ & $0.1 \mathrm{~mL}$ Sample solution & $2 \lambda$ & 4 \\
\hline B2 & $0.1 \mathrm{~mL} 1 \lambda$ & $0.1 \mathrm{~mL} \mathrm{Sample} \mathrm{solution}$ & $1 \lambda$ & 4 \\
\hline B3 & $0.1 \mathrm{~mL} 1 / 2 \lambda$ & $0.1 \mathrm{~mL} \mathrm{Sample} \mathrm{solution}$ & $1 / 2 \lambda$ & 4 \\
\hline B4 & $0.1 \mathrm{~mL} 1 / 4 \lambda$ & $0.1 \mathrm{~mL} \mathrm{Sample} \mathrm{solution}$ & $1 / 4 \lambda$ & 2 \\
\hline $\mathrm{C} 1$ & $0.1 \mathrm{~mL} 2 \lambda$ & $0.1 \mathrm{~mL} \mathrm{BET} \mathrm{water}$ & $1 \lambda$ & 2 \\
\hline $\mathrm{C} 2$ & $0.1 \mathrm{~mL} 1 \lambda$ & $0.1 \mathrm{~mL}$ BET water & $1 / 2 \lambda$ & 2 \\
\hline $\mathrm{C} 3$ & $0.1 \mathrm{~mL} 1 / 2 \lambda$ & $0.1 \mathrm{~mL}$ BET water & $1 / 4 \lambda$ & 2 \\
\hline $\mathrm{D}$ & $0.1 \mathrm{~mL} 1 / 4 \lambda$ & $0.1 \mathrm{~mL} \mathrm{BET}$ water & - & 2 \\
\hline
\end{tabular}

\section{BET for sample}

The test was performed using a TAL reagent having a sensitivity of $0.25 \mathrm{EU} / \mathrm{mL}$. Maximum Valid Dilution (MVD) is the maximum allowable dilution of the specimen where the endotoxin limit can be determined. A sample of the diluted solution was taken as much as $0.2 \mathrm{~mL}$ and added to the reagent TAL, then incubated at $37 \pm 1^{\circ} \mathrm{C}$ for $60 \pm 2$ minutes without vibration. The samples were tested positive for endotoxin ( $>0.25 \mathrm{EU} / \mathrm{mL}$ ) when the gel was formed and negative endotoxin $(<0.25$ $\mathrm{EU} / \mathrm{mL}$ ) were not formed after the tube was 
reversed 180 degree slowly. The maximum valid dilution in each sample was calculated by Equation 1. Table II shows the MVD values of some radiopharmaceutical kits based on Equation 1 (USP 35-NF 30 online version, 2012). The mechanism of gel formation in bacterial endotoxin test is shown in Figure 2.

MVD $=\frac{\text { (Endotoxin Limit } \mathrm{x} \text { Concentration of sample solution) }}{\lambda}$

In general, the radiopharmaceuticals labeled Tc-99m have a standard

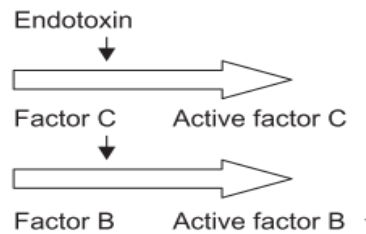

acceptability of endotoxin 175/V EU/mL (International Pharmacopoeia $8^{\text {th }} \mathrm{Ed}$, online version, 2018). In the hospital, the dose of radiopharmaceutical kit is a single dose, so the sample concentration should be one. In addition, the TAL reagent used has a sensitivity of $0.25 \mathrm{EU} / \mathrm{mL}$, so if included in Equation 1, the MVD value to be obtained is 680 times. This indicates if dilution is more than 680 times, the data to be obtained is invalid.

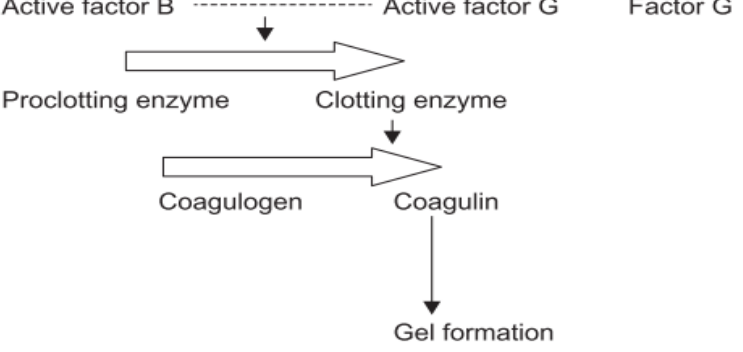

Figure 2. The reaction of gel formation in testing of endotoxin bacteria (Sandle, 2016)

The test sequence on the endotoxin assay should include solution A for the sample, solution B for positive product control (PPC), solution C for positive water control (PWC), and solution D for negative water control (NWC). The compositions of each sample solution are shown in Table III.

Table II. The Maximum Valid Dilution of MAA, tetrofosmin, and ethambutol

\begin{tabular}{lccc}
\hline \multicolumn{1}{c}{ Product } & Endotoxin limit & $\lambda$ & MVD \\
\hline MAA & $175 / \mathrm{V} \mathrm{EU} / \mathrm{mL}$ & $0.25 \mathrm{EU} / \mathrm{mL}$ & 680 \\
\hline Tetrofosmin & $175 / \mathrm{V} \mathrm{EU} / \mathrm{mL}$ & $0.25 \mathrm{EU} / \mathrm{mL}$ & 680 \\
\hline Ethambutol & $175 / \mathrm{V} \mathrm{EU} / \mathrm{mL}$ & $0.25 \mathrm{EU} / \mathrm{mL}$ & 680 \\
\hline
\end{tabular}

\section{Pyrogen test using Rabbit}

Pyrogen test using rabbit experimental animals was approved by the ethics commission for the use and maintenance of experimental animals - BATAN with approval number: 001/KEPPHPBATAN/IV/2016. Test were done in a separate chamber specific to the pyrogen test and with the same environmental conditions as the maintenance room, free of noise that might cause anxiety. In this test, three rabbits were used in one group. Rabbits were not fed during the testing time. Temperature measurement used a calibrated thermometer inserted into the rabbit's rectum. The thermometer probe is kept inside the rabbit's rectum, while holding the rabbit with a neck fitting that allows the rabbit to take a natural resting position. No more than 30 minutes before the injection of the test solution, the "initial temperature" of each rabbit was taken which is the basis for determining the temperature rise. The temperature difference of each rabbit in one group should not exceed $1{ }^{\circ} \mathrm{C}$ and the initial 
temperature of each rabbit should not exceed $39.8^{\circ} \mathrm{C}$. Unless otherwise stated in each monograph, the next step involved injecting the solution as much as $1.0 \mathrm{~mL}$, through the ear vein of the rabbit and the injection takes about 5 minutes. The test solution is a preparation which is constituted as shown in each monograph and is injected with the dose as indicated. For the pyrogen test of the injection device or apparatus a washing test solution was used or rinse from the surface of the apparatus which is directly related to the parenteral preparation, site of injection or tissue of the patient. All solutions should be free of contamination. After warming the solution at $37+2^{\circ} \mathrm{C}$ before injection the temperature was recorded consecutively between 1 and 3 hours after injection with a specific time interval. If no rabbit shows a temperature rise of $0.5^{\circ} \mathrm{C}$ or more above the temperature of each control, the product meets the requirements for the pyrogen-free (Silva et al., 2016).

Table III. Preparation of solutions for the bacteria endotoxin test

\begin{tabular}{lll}
\hline \multicolumn{1}{c}{ Solution } & \multicolumn{1}{c}{$\begin{array}{c}\text { Endotoxin concentration/ Solution to which } \\
\text { endotoxin is added }\end{array}$} & Number of replicates \\
\hline A (sample) & None/ $0.2 \mathrm{~mL}$ diluted sample solution & 2 \\
\hline $\mathrm{B}(\mathrm{PPC})$ & $0.1 \mathrm{~mL} 2 \lambda / 0.1 \mathrm{~mL}$ diluted sample solution & 2 \\
\hline $\mathrm{C}(\mathrm{PWC})$ & $0.1 \mathrm{~mL} 2 \lambda / 0.1 \mathrm{~mL}$ BET water & 2 \\
\hline $\mathrm{D}(\mathrm{NWC})$ & None $/ 0.2 \mathrm{~mL}$ BET water & 2 \\
\hline
\end{tabular}

\section{RESULTS AND DISCUSSION}

Testing of endotoxin bacteria using the tachypleus amoebocyte lysate (TAL) has become one of the alternative methods to quickly identify the number of endotoxin agents in pharmaceutical preparations. Before using a TAL kit for testing, it is important to verify the TAL kit used. This verification test to verify whether the TAL reagent used in accordance with the specification is listed. Generally, in the market there are several concentrations of TAL kits namely reagent TAL 0.25 $\mathrm{EU} / \mathrm{mL}, 0.125 \mathrm{EU} / \mathrm{mL}, 0.062 \mathrm{EU} / \mathrm{mL}$, $0.031 \mathrm{EU} / \mathrm{mL}$. In this research used TAL kit with sensitivity $0.25 \mathrm{EU} / \mathrm{mL}$. The verification test results of the TAL 0.25 $\mathrm{EU} / \mathrm{mL}$ kit are shown in Table IV.

Table IV. Results of Verification Test for TAL $0.25 \mathrm{EU} / \mathrm{mL}$

\begin{tabular}{ll}
\hline The concentration of Bacteria Endotoxin & Results \\
\hline $2 \lambda / 0.5 \mathrm{EU} / \mathrm{mL}$ & $(+)(+)(+)(+)$ \\
\hline $1 \lambda / 0.25 \mathrm{EU} / \mathrm{mL}$ & $(+)(+)(+)(+)$ \\
\hline $1 / 2 \lambda / 0.125 \mathrm{EU} / \mathrm{mL}$ & $(-)(-)(-)(-)$ \\
\hline $1 / 4 \lambda / 0.062 \mathrm{EU} / \mathrm{mL}$ & $(-)(-)(-)(-)$ \\
\hline $\mathrm{NWC}$ & $(-)(-)$ \\
\hline
\end{tabular}

The results of the confirmation test in Table IV are shown in accordance with the sensitivity of the TAL used. The endotoxin bacteria concentrations of 0.25 and 0.5 $\mathrm{EU} / \mathrm{mL}$ showed a positive sensitivity whereas concentrations of 0.125 and 0.062 $\mathrm{EU} / \mathrm{mL}$ were negative. The negative water control (BET water) showed negative. These results indicate that the sensitivity of TAL reagents tested for verification in accordance with the specification is 0.25 $\mathrm{EU} / \mathrm{mL}$. After the verification test was done, the next step was to test the inhibition/enhancement of the product to be tested. This test aimed to determine whether the chemical composition of the product to be measured inhibits or induces gel formation in the TAL reagent. The results of inhibition/enhancement test are shown in Table $\mathrm{V}$.

Table V. Results of the Inhibition / Enhancement test for MAA, tetrofosmin, and ethambutol kits 


\begin{tabular}{|c|c|c|c|c|c|c|c|c|c|c|c|c|c|c|c|c|}
\hline \multirow{2}{*}{ Solution } & \multicolumn{5}{|c|}{ MAA } & \multicolumn{5}{|c|}{ Tetrofosmin } & \multicolumn{5}{|c|}{ Ethambutol } & \multirow{2}{*}{ Requirement } \\
\hline & 1 & 2 & 3 & 4 & Conc. & 1 & 2 & 3 & 4 & Conc. & 1 & 2 & 3 & 4 & Conc. & \\
\hline $\mathrm{A}$ & - & - & - & - & $(-)$ & - & - & - & - & $(-)$ & - & - & - & - & $(-)$ & All negative (-) \\
\hline B1 & + & + & + & + & $(+)$ & + & + & + & + & $(+)$ & + & + & + & + & $(+)$ & All positive (+) \\
\hline B2 & + & + & + & + & $(+)$ & + & + & + & + & $(+)$ & + & + & + & - & $(+)$ & Min. 1 positive $(+)$ \\
\hline B3 & + & - & + & + & $(-)$ & + & + & - & + & $(-)$ & - & - & - & - & $(-)$ & Min. 1 negative (-) \\
\hline B4 & - & - & - & - & $(-)$ & - & - & - & - & $(-)$ & - & - & - & - & $(-)$ & All negative (-) \\
\hline $\mathrm{C} 1$ & + & + & & & $(+)$ & + & + & & & $(+)$ & + & + & & & $(+)$ & All positive (+) \\
\hline $\mathrm{C} 2$ & + & + & & & $(+)$ & + & + & & & $(+)$ & + & + & & & $(+)$ & Min. 1 positive $(+)$ \\
\hline $\mathrm{C} 3$ & - & - & & & $(-)$ & - & - & & & $(-)$ & - & - & & & $(-)$ & Min. 1 negative (-) \\
\hline $\mathrm{C} 4$ & - & - & & & $(-)$ & - & - & & & $(-)$ & - & - & & & $(-)$ & All negative (-) \\
\hline $\mathrm{D}$ & - & - & & & $(-)$ & - & - & & & $(-)$ & - & - & & & $(-)$ & All negative (-) \\
\hline
\end{tabular}

The A solution containing samples of MAA, tetrofosmin, and ethambutol and TAL reagents showed negative results. The B1 and B2 solutions contain samples and BE $2 \lambda$ and $1 \lambda$ served to see if the sample can inhibit gel formation. The results in B1 and B2 solutions were positive. Although there is a negative on one replica in sample B2 ethambutol, to get the conclusion at least one positive is needed so it remains concluded positive in solution B2. This result was confirmed by endotoxin concentration $2 \lambda$ and $1 \lambda$ plus BET water solution of $\mathrm{C} 1$ and $\mathrm{C} 2$ which also showed a positive. The $\mathrm{D}$ solution containing only BET water showed a negative.

In B3 and B4 solutions the result should show a negative because it contains samples plus endotoxin concentration $1 / 2 \lambda$ and $1 / 4 \lambda$. In addition to the results of the B3 and B4 solutions they serve to show whether the sample can induce gel formation in the TAL reagent. The results of MAA, tetrofosmin, and ethambutol samples showed negative. Although in MAA and tetrofosmin samples, three replicas in B3 showed positive but to get a conclusion at B3 that at least one replica is needed to show negative result hence it can be concluded the solution is negative. In comparison, $\mathrm{C} 3$ and $\mathrm{C} 4$ solutions containing endotoxin concentration $1 / 2 \lambda$ and $1 / 4 \lambda$ plus BET water showed negative.

The TAL verification test according to specification and inhibition/enhancement tests did not show result contrary to the requirements. Once the entire above test was done and the solution was qualified for acceptance then the next step is to test the sample in accordance with the MVD of each sample. In general, the endotoxin limit of radiopharmaceutical preparations is 175 $\mathrm{EU} / \mathrm{V}$. If the value is inserted in Equation 1 then the MVD obtained from the sample of MAA, tetrofosmin, and ethambutol is 680 times. This MVD is the maximum suggested dilution but dilution below this value does not cause problems. However, if dilution was done above of the MVD value then a possible wrong result could be found.

The pyrogen test was performed as a comparison in the sample determination. Although the pyrogen test results can show whether the samples cause heat, it still has some disadvantages. However, pyrogen tests using rabbits are difficult due to their size, and also the test results are affected by the environment or weather. Since the testing time is about 3 hours long, it requires a qualified analyst to make the injections and accurately measure the temperature. On the other side, the BET using TAL has several advantages because it is efficient and can be done in about onehour testing time, while the test results are easy to interpret, and the tool or testing process is easy to do.

The sample of MAA, tetrofosmin, ethambutol kits were randomized on three batches. One of the requirements of the gel clot reaction is the range $\mathrm{pH}$ around $6.0-$ 8.0. The BET consists of three batch samples, from PPC, PWC, and NWC solutions. The results of MAA, tetrofosmin, ethambutol using BET and pyrogen test are shown in Table VI. 
Table VI. Comparison bacteria endotoxin test using TAL reagent between pyrogenicity test using rabbit for radiopharmaceutical kits (MAA, tetrofosmin, and ethambutol)

\begin{tabular}{lllllll}
\multirow{2}{*}{ Radiopharmaceutical } & \multicolumn{7}{c}{ BET test } & \multirow{2}{*}{ Pyrogenicity test } \\
\cline { 2 - 6 } & pH & Sample & PPC & PWC & NWC & \\
\hline Kit MAA & \multicolumn{7}{c}{$(-0)(-)$} & $(+)(+)$ & $(+)(+)$ & $(-)(-)$ & $(-)(-)(-)$ \\
\hline Batch 1 & 6.0 & $(-)(-)$ & $(+)(+)$ & $(+)(+)$ & $(-)(-)$ & $(-)(-)(-)$ \\
\hline Batch 2 & 6.0 & $(-)(-)$ & $(+)(+)$ & $(+)(+)$ & $(-)(-)$ & $(-)(-)(-)$ \\
\hline Batch 3 & \multicolumn{7}{c}{$(-)$} & $(+)$ & $(+)$ & $(-)$ & $(-)$ \\
\hline Conc. & 7.0 & $(-)(-)$ & $(+)(+)$ & $(+)(+)$ & $(-)(-)$ & $(-)(-)(-)$ \\
\hline Kit Tetrofosmin & 7.0 & $(-)(-)$ & $(+)(+)$ & $(+)(+)$ & $(-)(-)$ & $(-)(-)(-)$ \\
\hline Batch 1 & 7.0 & $(-)(-)$ & $(+)(+)$ & $(+)(+)$ & $(-)(-)$ & $(-)(-)(-)$ \\
\hline Batch 2 & \multicolumn{7}{c}{$(-)$} & $(+)$ & $(+)$ & $(-)$ & $(-)$ \\
\hline Batch 3 & \multicolumn{7}{c}{} & & & \\
\hline Conc. & 8.0 & $(-)(-)$ & $(+)(+)$ & $(+)(+)$ & $(-)(-)$ & $(-)(-)(-)$ \\
\hline Kit Ethambutol & 8.0 & $(-)(-)$ & $(+)(+)$ & $(+)(+)$ & $(-)(-)$ & $(-)(-)(-)$ \\
\hline Batch 1 & 8.0 & $(-)(-)$ & $(+)(+)$ & $(+)(+)$ & $(-)(-)$ & $(-)(-)(-)$ \\
\hline Batch 2 & \multicolumn{7}{c}{$(-)$} & $(+)$ & $(+)$ & $(-)$ & $(-)$
\end{tabular}

Table VI shows the endotoxin test results on MAA, tetrofosmin, and ethambutol kits of three batches. The effective $\mathrm{pH}$ required for endotoxin testing using TAL is in the range $6.0-8.0$ [15]. MAA samples have a $\mathrm{pH}$ of 6.0 , tetrofosmin of 7.0, while the highest ethambutol of 8.0. The endotoxin test results for MAA, tetrofosmin, and ethambutol samples showed negative, while PPC containing samples plus endotoxin concentration $2 \lambda$ showed positive, PWC containing endotoxin concentration $2 \lambda$ plus BET water showed positive and NWC containing BET water showed negative. The results of endotoxin testing using TAL reagents $0.25 \mathrm{EU} / \mathrm{mL}$ showed that samples of MAA, tetrofosmin, and ethambutol contained no endotoxin over $0.25 \mathrm{EU} / \mathrm{mL}(<0.25 \mathrm{EU} / \mathrm{mL})$.

The MAA, tetrofosmin and ethambutol samples were tested using the rabbit pyrogen test. Table VI shows the results of the pyrogen test in each replica of the test in MAA, tetrofosmin, and ethambutol samples were negative. This result can be inferred negative because there is no single rabbit that indicated a temperature increase of $0.5 \mathrm{oC}$ or more. The result of endotoxin testing showed that the value of less than $0.25 \mathrm{EU} / \mathrm{mL}$ was in accordance with the pyrogen test results showing that all MAA, tetrofosmin and ethambutol products did not cause fever in rabbits.

\section{CONCLUSION}

Based on the results of the TAL reagent verification tests, all samples showed values corresponding to the standards of $2 \lambda$ $=(+), 1 \lambda=(+), 1 / 2 \lambda=(-), 1 / 4 \lambda=(-)$, and NWC $=(-)$ Furthermore, inhibition/enhancement tests for MAA, tetrofosmin, and ethambutol products demonstrated to be non-inhibiting or gelinducing, and these results are in accordance with acceptability standards so that the samples can be tested using TAL reagents. The results of MAA, tetrofosmin, and ethambutol product testing on three batches with $\mathrm{pH}$ according to test range (6.0 - 8.0) were a sample $=(-), \mathrm{PPC}=(+)$, PWC $=(+)$, and NWC $=(-)$. The same results were obtained from the pyrogen test using rabbits.

\section{ACKNOWLEDGEMENT}

Author would like to thank the Head of Center for Radioisotope and Radiopharmaceutical Technology for providing support for this research activity. I am also thankful for the team of quality 
control of radioisotope and radiopharmaceuticals.

\section{REFERENCES}

Bang, F. B., 1971. A factor in crab amebocytes which stimulates in vitro clotting of crab blood. Journal of Invertebrate Pathology, 18(2), 280-283.

John, B.A., Kamaruzzaman, B.Y., Jalal, K.A., and Zaleha, K., 2012. TAL - a source of bacterial endotoxin detector in liquid biological samples. International Food Research Journal, 19(2), 423-425.

Juwita, R., 2009. Biological evaluation of $99 \mathrm{mTc}$-ethambutol for early detection of tuberculosis infection in animal model. Indonesian Journal of Pharmacy, 20(2), 55-61.

Knapp, F. R. and Dash, A., 2016. Introduction: Radiopharmaceuticals Play an Role in Both Diagnostic and Therapeutic Nuclear Medicine, in Radiopharmaceuticals for Therapy. New York: Springer, 6.

Lestari, W., 2017. Formulation of Macroagregated Albumin (MAA) Kit for Lung Perfusion, in National Seminar on Nuclear Technology Utilization. 2017. Tangerang Selatan, 27-32.

Li, H., Hitchins, V. M. and Wickramasekara, S., 2016. Rapid detection of bacterial endotoxins in ophthalmic viscosurgical device materials by direct analysis in real time mass spectrometry. Analytica Chimica Acta, 943, 98-105.

Lopes, I.G., Silva, C.C., Presgrave, O.A., and Bôas, M.H, 2015. Assessment of pyrogenic response of lipoteichoic acid by the monocyte activation test and the rabbit pyrogen test. Regulatory Toxicology and Pharmacology, 73(1), 356-360.

Miao, P., Han, K.W., Qi, J., Zhang, C., and Liu, T., 2013. Electrochemical investigation of endotoxin induced limulus amebocyte lysate gel-clot process. Electrochemistry Communications, 26(1), 29-32.

Ochiai, M., Yamamoto, A.H., Naito, S., Maeyama, J., Masumi, A., Hamaguchi, I., Horiuchi, Y., and Yamaguchi, K., 2010. Applicability of bacterial endotoxins test to various blood products by the use of endotoxin-specific lysates. Biologicals, 38(6), 629-636.

Salmanoglu, E., Kim, S. and Thakur, M. L., 2018. Currently Available Radiopharmaceuticals for Imaging Infection and the Holy Grail. Seminars in Nuclear Medicine. 2018. Elsevier Inc., 48(2), pp. 8699.

Sandle, T., 2016. Endotoxin and pyrogen testing, in Pharmaceutical Microbiology. 80th ed. Kidlington: Woodhead Publishing, 131-145.

Scott, P. J. H. and Kilbourn, M. R., 2015. Radiochemical Syntheses, Volume 2: Further Radiopharmaceuticals for Positron Emission Tomography and New Strategies for Their Production. New Jersey: John Wiley \& Sons, Inc.

Sharma, S., Mittal, B. R., Vatsa, R., and Singh, B, 2011. Gel clot bacterial endotoxin test of FDG: Indian scenario. Indian journal of nuclear medicine: the official journal of the Society of Nuclear Medicine, 26(3), 149-52.

Silva D. C. C. Presgrave,O.A.F., Hartung, T., Moraes, A.M.L., and Delgado, I.F., 2016. Applicability of the Monocyte Activation Test (MAT) for hyperimmune sera in the routine of the quality control laboratory: Comparison with the Rabbit Pyrogen Test (RPT). Toxicology in Vitro, 32, 70-75. 
USP 35-NF 30 online version, 2012. United

States, General Chapters/

Biological Tests and Assays <85>

Bacterial Endotoxins Test.

Available from:

https://www.drugfuture.com/Pharm acopoeia/usp35/PDF/56255630\%2

$0 \% 5 \mathrm{~b} 85 \% 5 \mathrm{~d} \% 20 \mathrm{Bacterial} \% 20 \mathrm{End}$ otoxins\%20Test.pdf. [Accessed January 1, 2019].

Widyastuti, W., Lestari, E. and Sangaji, D., 2017. Effect of Radioactivity of Technetium-99m on the Autosterilization Process of nonsterile Tetrofosmin Kits. The Journal of Pure and Applied Chemistry Research, 6(1), 57-63.

The International Pharmacopoeia, Eight Edition, online version, 2018. New Zealand, Monoghraph: Technetium $(99 \mathrm{mTc})$ tetrofosmin complex injection (Technetii (99mTc) tetrofosmini multiplex injectio). Available from: https://apps.who.int/phint/pdf/b/6.3 .2.24.Technetium-(99mTc)tetrofosmin-complex-injection(_.pdf [Accessed May 1, 2019].

Zandieh, M., Hosseini, S.N., Vossoughi, M., Khatami, M., Abbasian, S., and Moshaii, A., 2018. Label-free and simple detection of endotoxins using a sensitive LSPR biosensor based on silver nanocolumns. Analytical Biochemistry. Elsevier, 548 (February), 96-101. 